\title{
Efeito da suplementação com ácido linoléico conjugado e do treinamento em natação sobre a composição corporal e os parâmetros bioquímicos de ratos Wistar em crescimento
}

\section{$\int$}

ORIGINAL | ORIGINAL

Effect of conjugated linoleic acid supplementation

and swimming training on the body composition

and biochemical parameters of Wistar pups

Antonio Eduardo de AQUINO JUNIOR ${ }^{1,2}$

Grace Kelly Zanotti Simões DOURADO ${ }^{3}$

Fernanda Oliveira DUARTE²

Ana Cláudia Garcia Oliveira DUARTE²

Marcela SENE-FIORESE 2,4

\section{RE S U M O}

\section{Objetivo}

Avaliar os efeitos da suplementação com ácido linoléico conjugado, associada ao treinamento moderado em natação, sobre a composição corporal, o consumo e a eficiência alimentar, a glicemia, o perfil lipídico e o glicogênio muscular e hepático de ratos Wistar.

\section{Métodos}

Ratos Wistar (30 dias) foram divididos em: sedentário, sedentário suplementado, treinado e treinado suplementado. Permaneceram em gaiolas individuais com comida e água ad libitum, temperatura de $23^{\circ} \mathrm{C}$ (com variação de $1^{\circ} \mathrm{C}$ ) e ciclo claro-escuro de 12 horas, durante 8 semanas. A sessão de natação durou 1 hora e foi realizada três vezes/semana, bem como a suplementação com ácido linoléico conjugado a $2 \%$. Após

\footnotetext{
1 Universidade Federal de São Carlos, Programa de Especialização em Fisiologia do Exercício. Rod. Washington Luís, SP-310, km 235, 13565-905, São Carlos, SP, Brasil. Correspondência para/Correspondence to: A.E. AQUINO JÚNIOR. E-mail: <spydera@ig.com.br>.

${ }^{2}$ Universidade Federal de São Carlos, Departamento de Educação Física e Motricidade Humana, Laboratório de Nutrição e

Metabolismo Aplicados ao Exercício. São Carlos, SP, Brasil.

${ }^{3}$ Universidade Estadual Paulista, Pós-Graduação em Ciências Nutricionais. Araraquara, SP, Brasil.

${ }^{4}$ Universidade Camilo Castelo Branco, Faculdade de Educação Física. Descalvado, SP, Brasil.
} 
494 A.E. AQUINO JUNIOR et al.

sacrifício, o plasma, os tecidos adiposos brancos e o marrom, o músculo gastrocnêmio e o fígado foram coletados e pesados.

\section{Resultados}

A suplementação per se não promoveu modificação na ingestão alimentar e na massa corporal dos animais. Houve aumento na glicemia de jejum $(p<0,05)$, nas lipoproteínas de alta densidade $(p<0,05)$, no colesterol total $(p<0,05)$ e redução dos triacilgliceróis. A suplementação associada ao treinamento reduziu a massa corporal $(p<0,05)$ e aumentou o peso relativo do tecido adiposo, do fígado e a glicemia de jejum.

\section{Conclusão}

A suplementação com ácido linoléico conjugado associada à prática de exercício físico parece ter influência no balanço energético, mas, por outro lado, o aumento no peso do fígado indica que a ingestão deste ácido graxo pode ter efeitos indesejáveis, aumentando as chances de desenvolvimento do fígado gorduroso. Estes achados apontam perspectivas para novos estudos envolvendo análises histológicas do fígado, expressão gênica de enzimas chaves do metabolismo lipídico e de carboidratos, associados ou não a diferentes protocolos de treinamento físico.

Termos de indexação: Ácidos linoléicos. Estudos experimentais. Natação. Ratos.

\section{A B S T R A C T}

\section{Objective}

The objective of this study was to evaluate the effects of conjugated linoleic acid supplementation associated with moderate swimming training on body composition, food efficiency and consumption, blood glucose, lipid profile, and muscle and liver glycogen of Wistar rats.

\section{Methods}

Thirty-day old Wistar rats were divided into the following groups: inactive, inactive with 2\% conjugated linoleic acid supplementation, active, and active with $2 \%$ conjugated linoleic acid supplementation. They remained in individual cages with food and water ad libitum, temperature of $23 \pm 1^{\circ} \mathrm{C}$ and a light and dark cycle of 12 hours for 8 weeks. The active groups swam for one hour three times per week. The animals were killed and the plasma, white and brown fat tissues, gastrocnemius muscle and liver were collected and weighted.

\section{Results}

Supplementation per se did not promote food intake or body weight changes in the animals. Fasting glucose $(p<0.05)$ and high density lipoproteins (HDL, $p<0.05)$ increased and triacylglycerols decreased. Supplementation associated with activity decreased body mass $(p<0.05)$ and increased the relative weight of fat tissues, liver and fasting glucose.

\section{Conclusion}

Conjugated linoleic acid supplementation associated with physical activity seems to influence energy balance. On the other hand, the increased liver weight indicates that intake of this fatty acid may have undesirable sideeffects, increasing the chances of developing fatty liver. This new perspective makes way for new studies including histological analyses of the liver and gene expression of key enzymes from the lipid and carbohydrate metabolism, associated or not with different physical training protocols.

Indexing terms: Linoleic acid. Experimental studies. Swimming. Rats.

\section{N T R O D U ÇÃ O}

O Ácido Linoléico Conjugado (CLA) é classificado como um grupo de isômeros de posição e geométricos com duplas ligações conjugadas do ácido octadecadienóico (C18: 2), em que as duplas ligações são conjugadas em vez de existirem na configuração interrompida metilênica típica ${ }^{1-3}$. Nove isômeros diferentes do CLA foram relatados como de ocorrência natural nos alimentos, sendo o 9-cis;11-trans (9-c;11-t) o de maior ocorrência. Este isômero está incorporado 
à membrana plasmática e parece ter relação com propriedades anticarcinogênicas e com a melhora da performance no crescimento dos animais. Já o isômero 10-trans; 12-cis (10-t; 12-c) não está incorporado às membranas e parece ter maior relação com o metabolismo energético ${ }^{1,3}$.

A habilidade do ácido linoléico conjugado em alterar a composição corporal, aumentando a massa magra e reduzindo a massa gorda em diferentes espécies, tais como: camundongos, hamsters, ratos, porcos e humanos tem sido amplamente estudada ${ }^{4-7}$. Devido a seu suposto potencial benéfico, como manutenção/redução da massa corporal e do percentual de gordura, o CLA tem sido denominado como um possível fator para o controle de doenças, como a obesidade ${ }^{4}$. O efeito do CLA na prevenção e no tratamento do diabetes mellitus tipo 2 parece estar associado à dose, ao isômero, à espécie, ao sexo e, principalmente, à existência prévia de obesidade e de resistência á ação da insulina ${ }^{8,9}$.

Essa discussão a respeito da suplementação com CLA tem aumentado frente aos resultados, muitas vezes controversos, encontrados por pesquisadores. Nesse contexto é importante ressaltar que alguns efeitos indesejáveis, como o aumento da resistência à insulina, a hiperglicemia e a hiperinsulinemia de jejum, relacionados ao uso do CLA, foram encontrados tanto em estudos com humanos como em animais ${ }^{10}$. Nesse sentido, a dieta balanceada e o exercício físico regular têm sido apontados como medidas terapêuticas no processo de prevenção e atenuação da obesidade e de outras doenças metabólicas, devido à promoção de importantes alterações no metabolismo lipídico, à diminuição no percentual de gordura corporal e ao aumento da massa magra. Assim, os resultados de pesquisas envolvendo o uso do ácido linoléico conjugado como coadjuvante no controle de peso e aumento de massa magra, tem levado ao uso indiscriminado de uma mistura sintética de isômeros do CLA (9-c, 11-t; 10-t, 12-c) por praticantes de exercício físico. Desse modo, é importante ressaltar que o uso de animais em protocolos experimentais deve mimetizar as particularidades do treinamento físico, da dieta entre outras variáveis correspondentes em seres humanos ${ }^{11}$. Devido a este fato, objetivou-se neste estudo simular os efeitos da suplementação de uma mistura comercial de ácido linoléico conjugado, associada ao treinamento físico moderado de natação sobre a composição corporal, o consumo e a eficiência alimentar, o perfil lipídico, a glicemia de jejum e o glicogênio muscular e hepático de ratos Wistar em crescimento.

\section{MÉ TO D O S}

Para este experimento foram utilizados 34 ratos da linhagem Wistar, com 21 dias de vida, procedentes do Biotério Central da Universidade Federal de São Carlos (SP). Os animais foram previamente adaptados durante sete dias ao ambiente do Laboratório de Nutrição e Metabolismo do Departamento de Educação Física. Durante todo o período experimental de oito semanas, os animais permaneceram em gaiolas individuais de polipropileno $(30 \times 20 \times 13 \mathrm{~cm})$, com água e ração ad libitum, com temperatura controlada de $23^{\circ} \mathrm{C}$ (com variação de $1^{\circ} \mathrm{C}$ ) e foto período claro-escuro de 12 horas. O projeto foi aprovado pelo Comitê de Ética em Pesquisa de Experimentação Animal da Universidade Federal de São Carlos (CCEA/UFSCar), de acordo com o protocolo $\mathrm{n}^{\circ}$ 055/2007.

Animais com 30 dias de vida pesando em média 88g (Desvio-padrão - DP=5) foram divididos aleatoriamente em 4 grupos: grupo sedentário (S, $n=8)$; grupo treinado $(T, n=8)$; grupo sedentário suplementado com CLA (SS, $n=9)$; grupo treinado suplementado com CLA (TS, $n=9)$. Todos os animais foram alimentados ad libitum com dieta padrão PRIMOR ${ }^{\circledR}$ (São Paulo, Brasil) em forma de pellets, própria para roedores. De acordo com o fabricante, cada $100 \mathrm{~g}$ de dieta contém: $23 \mathrm{~g}$ de proteína, $49 \mathrm{~g}$ de carboidrato, $4 \mathrm{~g}$ de gordura, $5 \mathrm{~g}$ de fibra, $7 \mathrm{~g}$ de cinza e $6 \mathrm{~g}$ de vitaminas.

A massa corporal e o consumo alimentar foram controlados durante todo o período experimental. O consumo alimentar foi calculado a 
496 | A.E. AQUINO JUNIOR et al.

partir da diferença de peso entre a ração ofertada e o resto do dia anterior, sendo que a ração ofertada foi em forma de pellet e esta foi colocada sobre a grade da caixa para evitar eventual desperdício. Já a eficiência alimentar foi calculada diariamente a partir do ganho de massa corporal, dividido pelo consumo alimentar, sendo posteriormente calculada a média da semana ${ }^{12}$.

Os animais dos grupos treinados realizaram treinamento moderado de natação em tanques individuais $(60 \mathrm{~cm}$ de profundidade), com água mantida à temperatura de $30^{\circ} \mathrm{C}$ (com variação de $2^{\circ} \mathrm{C}$ ). Cada sessão de natação teve duração de 60 de minutos e foram realizadas três vezes na semana em dias alternados. Foi adicionada sobrecarga de $5 \%$ da massa corporal atada à cauda de cada animal, para que os animais não ficassem flutuando, mensurada previamente a cada sessão de treinamento ${ }^{13}$.

Os animais suplementados receberam ácido linoléico conjugado sintético da marca Probiótica ${ }^{\circledR}$, uma mistura dos isômeros (9-t, 11-c; $10-c, 12-t$ ), quantificado a $2 \%$ do total do consumo alimentar diário, 1 hora antes do início de cada sessão de natação. Realizou-se a suplementação com CLA por meio de entubação orogástrica com seringa descartável de $1 \mathrm{~mL}$ e agulha de gavage ${ }^{14}$. Os animais que não receberam suplementação foram submetidos à gavagem utilizando água como veículo, para eliminar a influência do estresse promovido pelo procedimento.

Ao final de oito semanas de tratamento, todos os animais foram sacrificados por decapitação em guilhotina. Os tecidos adiposos brancos Epididimal (EPI), Retroperitoneal (RET) e Visceral (VISC), o Tecido Adiposo Marrom (TAM), o Fígado (FIG) e o Músculo Gastrocnêmio (GAST) foram coletados, pesados e estocados em freezer a $-20^{\circ} \mathrm{C}$. O sangue foi coletado em tubos não heparinizados, centrifugado (para obtenção do soro) e analisado imediatamente após a coleta.

Imediatamente após a obtenção do soro, alíquotas foram utilizadas para mensuração de concentração de glicose, colesterol total, lipopro- teína de baixa densidade (HDL-colesterol) e triacilglicerol. Kits comerciais da marca Laborlab ${ }^{\circledR}$ foram utilizados e as amostras foram analisadas por método enzimático colorimétrico com leitura em espectrofotômetro ultravioleta (mode/ UV-160 1PC, Shimadzu Corporation, Kyoto, Japan).

A concentração hepática e muscular de glicogênio foi quantificada por método colorimétrico, o qual avalia a concentração de glicosilglicose utilizando-se um padrão de 100nmols de glicose ${ }^{15}$. A leitura foi realizada em espectro-fotômetro (480nm), modelo UV -1601PC (Shimadzu Corporation, Kyoto, Japan) e os valores foram apresentados em mmols glicosil-glicose/g tecido.

Os resultados estão expressos como média e desvio-padrão (DP). Para a análise dos dados foi utilizado o software Instat 3.0 for Windons 95 (GraphPad, San Diego, CA, USA, 1998). As comparações foram realizadas pelo teste de variância ANOVA two-way e foi aplicado Teste de Tukey-Kramer, para verificação de diferenças estatísticas entre as médias, com nível de significância de $p<0,05$ para as variáveis analisadas.

\section{RESULTADOS E DISCUSS ÃO}

\section{Suplementação com ácido linoléico conjugado e sedentarismo}

A suplementação com CLA, administrada em animais sedentários, não promoveu alterações significantes, quando comparadas às do grupo sedentário (S x SS) em relação à evolução da massa corporal (Figura 1), ao consumo alimentar (Figura 2) e à eficiência alimentar (Figura 3). Entretanto, houve diminuição do peso relativo do tecido retroperitoneal, como demonstra a Tabela 1. De acordo com recente revisão realizada por Mourão et al. ${ }^{1}$, animais suplementados com ácido linoléico conjugado reduzem a gordura corporal apresentando efeitos variados na perda de peso. Estes dados controversos podem ser explicados devido aos diferentes tipos de isômeros do CLA, às diferentes dosagens administradas e aos diferentes animais utilizados em pesquisas ${ }^{16}$. 


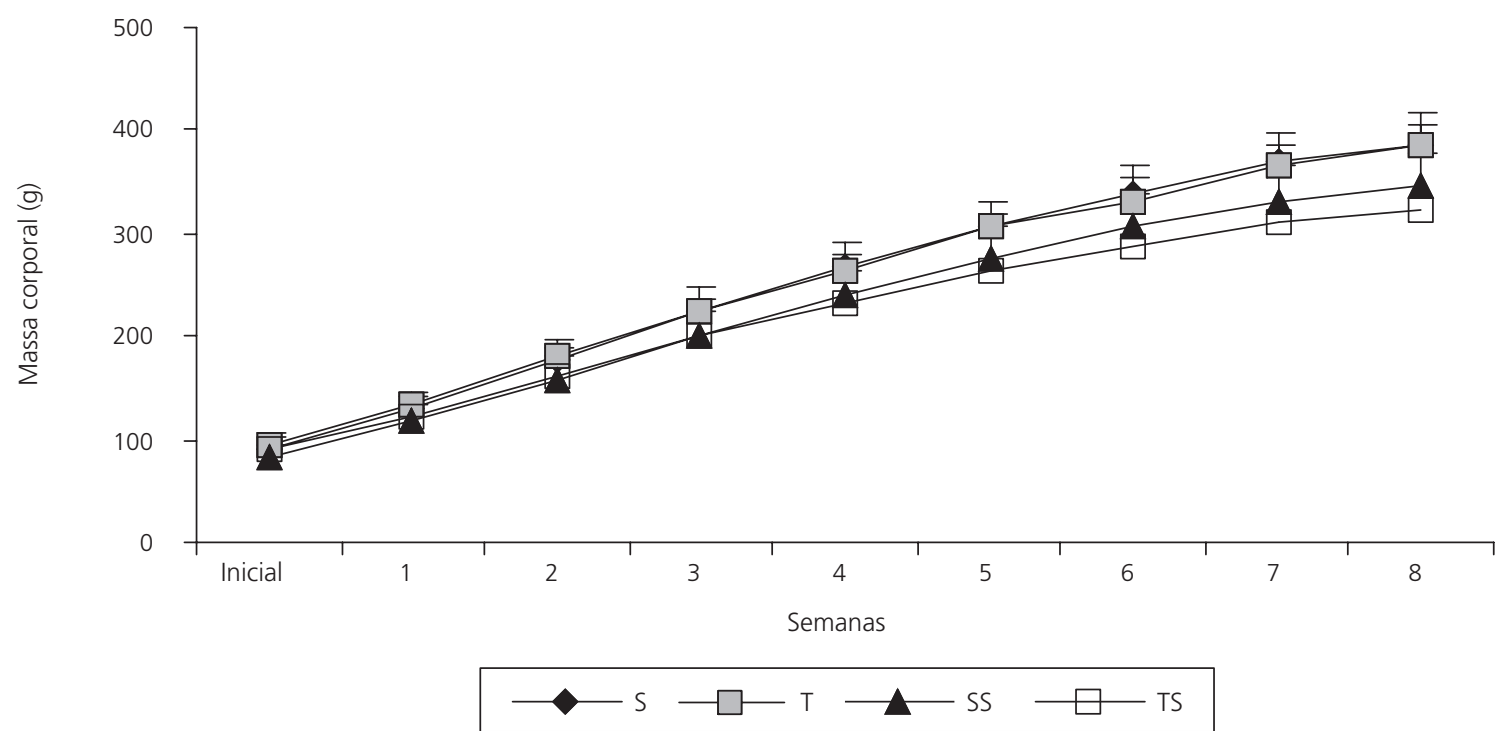

Figura 1. Evolução da massa corporal (gramas) de ratos submetidos à suplementação com ácido linoléico conjugado e/ou ao treinamento de natação, por 8 semanas. São Carlos (SP), 2007.

Nota: Os valores estão expressos como média e desvio-padrão. Diferentes subscritos: *versus $S_{;}{ }^{+}$versus $T$, para $p<0,05$. S: sedentário não suplementado $(n=8)$; T: treinado não suplementado $(n=8)$; SS: sedentário suplementado $(n=9)$; TS: treinado suplementado $(n=8)$; g: grama.

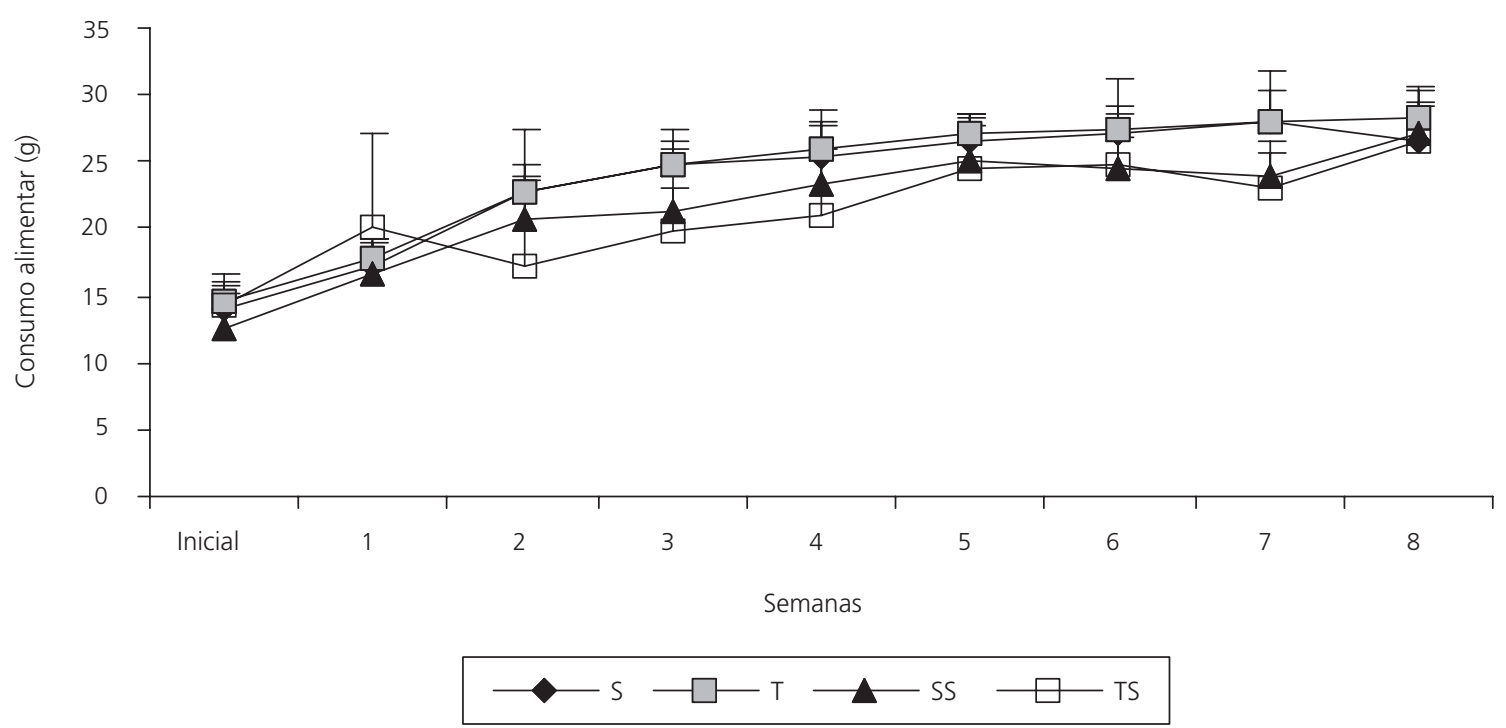

Figura 2. Evolução semanal do consumo alimentar (gramas) de ratos submetidos à suplementação com ácido linoléico conjugado e/ou ao treinamento de natação, por 8 semanas. São Carlos (SP), 2007.

Nota: Os valores estão expressos como média e desvio-padrão. Diferentes subscritos: *versus $S_{\text {; }}{ }^{+}$versus $T$, para $p<0,05$. S: sedentário não suplementado $(n=8)$; T: treinado não suplementado $(n=8)$; SS: sedentário suplementado $(n=8)$; TS: treinado suplementado $(n=8)$; g: grama. 
498 | A.E. AQUINO JUNIOR et al.

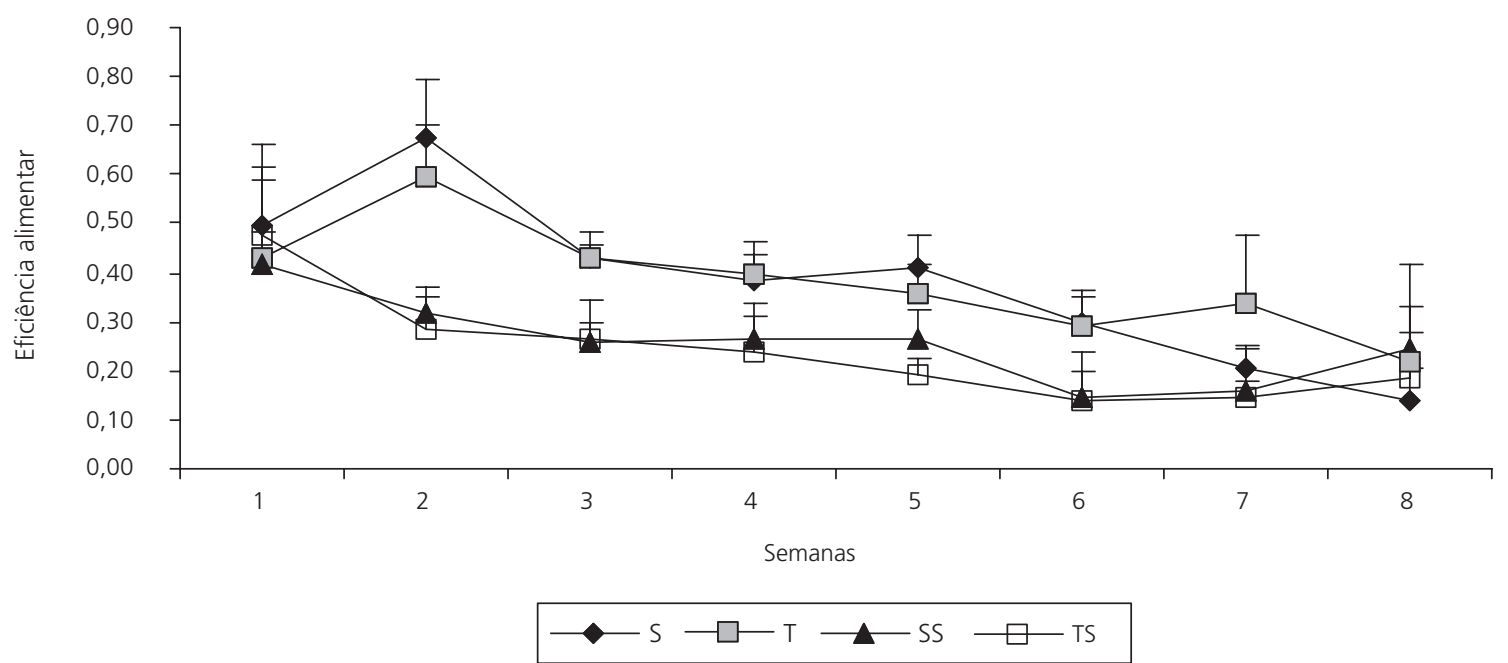

Figura 3. Eficiência alimentar de ratos submetidos à suplementação com ácido linoléico conjugado e/ou ao treinamento de natação, por 8 semanas. São Carlos (SP), 2007.

Nota: Os valores estão expressos como média e desvio-padrão. Diferentes subscritos: "versus S; ${ }^{+}$versus T, para p<0,05. S: sedentário não suplementado $(n=8)$; T: treinado não suplementado $(n=8)$; SS: sedentário suplementado $(n=9)$; TS: treinado suplementado ( $n=9$ ).

Em outro estudo realizado com camundongos, tratados com CLA $2 \%$ durante 5 ou 14 dias, os autores verificaram aumento de quatro vezes na incidência de apoptose no tecido adiposo retroperitoneal| ${ }^{17}$, o que poderia estar parcialmente de acordo com os resultados observados na Tabela 1. Além disso, outros estudos têm demonstrado as várias possibilidades de mecanismos de ação do CLA, sendo reportado o aumento na atividade da Lípase Hormônio Sensível (LHS), e, portanto aumento da lipólise em adipócitos, acompanhado por uma maior oxidação de Ácidos Graxos (AG) tanto no músculo esquelético quanto no tecido adiposo, pelo aumento da atividade da Carnitina-Palmitoil-Transferase (CPT) ${ }^{9}$. O efeito de redução do tecido adiposo retroperitoneal pode ser importante, pois seu acúmulo contribui para o aumento da adiposidade intra-abdominal aumentando as chances de desenvolvimento da obesidade e, conseqüentemente, de doenças correlacionadas, como diabetes mellitus tipo 2, resistência à ação da insulina e doenças cardiovasculares ${ }^{18}$.

Em relação ao tecido adiposo marrom a suplementação promoveu diminuição em seu peso relativo (Tabela 1), sugerindo efeitos específicos do ácido linoléico conjugado sobre a termogênese, conforme demonstrado em estudo prévio de Takahashi et al. ${ }^{19}$. Sabe-se que o TAM é um importante sítio regulador da homeostase térmica e pode ser induzido de forma aguda pela administração de hormônios tireoidianos, pela estimulação simpática, pelo frio, bem como pela ingestão alimentar ${ }^{20}$.

Um dado importante observado neste estudo foi o aumento do peso relativo do fígado decorrente da suplementação com CLA. Estudos mostraram que a suplementação alimentar com estes isômeros promove aumento do peso relativo do fígado ${ }^{21}$, bem como aumento no acúmulo de gordura neste órgão ${ }^{22}$. Ohnuki et al. ${ }^{22}$ observaram, em camundongos suplementados com ácido linoléico conjugado $1 \%$, aumento no peso do fígado, sendo que em alguns animais houve o desenvolvimento de fígado gorduroso. Com base nesses estudos, pode-se sugerir que, nesta pesquisa, a suplementação com ácido linoléico conjugado deva ter aumentado o armazenamento de triacilglicerol no fígado, justificando o aumento no peso deste tecido (Tabela 1) e a redução na concentração sérica de triacilglicerol. Além disso, houve aumento na glicemia de jejum nos animais 
sedentários suplementados, fato que pode ter contribuído para o aumento nos estoques de glicogênio muscular. A manutenção no teor de glicogênio hepático associada ao aumento na glicemia pode sugerir que o fígado esteja entrando em um processo de resistência à ação da insulina, uma vez que este é o maior órgão responsável pela manutenção da homeostase glicêmica (Tabela 2).

\section{Suplementação com ácido linoléico conjugado e treinamento físico}

O treinamento físico regular tem sido utilizado como importante estratégia para a promoção da saúde e o controle de doenças crônicas não-transmissíveis ${ }^{23}$. Estudos experimentais têm mostrado que o exercício moderado de natação, quando associado à dieta balanceada reduz a adipo-

Tabela 1. Peso relativo dos tecidos (g de tecido/100g de peso corporal) de ratos submetidos à suplementação com ácido linoléico conjugado e/ou ao treinamento de natação, por 8 semanas. São Carlos (SP), 2007.

\begin{tabular}{|c|c|c|c|c|c|c|c|c|}
\hline \multirow[b]{2}{*}{ Tecidos } & \multicolumn{2}{|c|}{ Grupo S } & \multicolumn{2}{|c|}{ Grupo T } & \multicolumn{2}{|c|}{ Grupo SS } & \multicolumn{2}{|c|}{ Grupo TS } \\
\hline & $M$ & DP & $M$ & DP & $\mathrm{M}$ & DP & $M$ & DP \\
\hline \multirow[t]{2}{*}{ EPI } & 0,81 & 0,12 & 0,75 & 0,15 & 0,71 & 0,19 & 1,06 & $0,20^{*}+$ \\
\hline & \multicolumn{2}{|c|}{$(n=8)$} & \multicolumn{2}{|c|}{$(n=8)$} & \multicolumn{2}{|c|}{$(n=9)$} & \multicolumn{2}{|c|}{$(n=9)$} \\
\hline \multirow[t]{2}{*}{ RET } & 1,34 & 0,13 & 1,27 & 0,20 & 0,96 & $0,09^{*}$ & 1,02 & $0,15^{*}$ \\
\hline & \multicolumn{2}{|c|}{$(n=8)$} & \multicolumn{2}{|c|}{$(n=8)$} & \multicolumn{2}{|c|}{$(n=9)$} & \multicolumn{2}{|c|}{$(n=9)$} \\
\hline VIS & \multicolumn{2}{|c|}{$(n=8)$} & \multicolumn{2}{|c|}{$(n=8)$} & \multicolumn{2}{|c|}{$(n=9)$} & \multicolumn{2}{|c|}{$(n=9)$} \\
\hline \multirow[t]{2}{*}{ TAM } & 0,12 & 0,02 & 0,20 & $0,04^{*}$ & 0,06 & $0,02^{*}$ & 0,05 & $0,02^{*+}$ \\
\hline & \multicolumn{2}{|c|}{$(n=8)$} & \multicolumn{2}{|c|}{$(n=8)$} & \multicolumn{2}{|c|}{$(n=9)$} & \multicolumn{2}{|c|}{$(n=9)$} \\
\hline \multirow[t]{2}{*}{ GAST } & 0,50 & 0,04 & 0,50 & 0,03 & 0,50 & 0,012 & 0,51 & 0,03 \\
\hline & \multicolumn{2}{|c|}{$(n=8)$} & \multicolumn{2}{|c|}{$(n=8)$} & \multicolumn{2}{|c|}{$(n=9)$} & \multicolumn{2}{|c|}{$(n=9)$} \\
\hline
\end{tabular}

Valores expressos em média e desvio-padrão. Diferentes subscritos: *versus S: ${ }^{+}$versus T, para $p<0,05$. S: sedentário não suplementado; T: treinado não suplementado; SS: sedentário suplementado; TS: treinado suplementado; EPI: tecido adiposo epididimal; RET: tecido adiposo retroperitoneal; VIS: tecido adiposo visceral; TAM: tecido adiposo marrom; GAST: músculo gastrocnêmio; FIG: fígado; g: grama.

Tabela 2. Concentrações séricas de glicose, colesterol total, HDL-colesterol e triacilglicerol (mg/dL) e teor de glicogênio muscular e hepático (mmol de glicosil-glicose/g tecido) de ratos submetidos à suplementação com ácido linoléico conjugado e/ou ao treinamento de natação, por 8 semanas. São Carlos (SP), 2007.

\begin{tabular}{|c|c|c|c|c|c|c|c|c|}
\hline \multirow{2}{*}{$\begin{array}{l}\text { Concentrações } \\
\text { séricas }\end{array}$} & \multicolumn{2}{|c|}{ Grupo S } & \multicolumn{2}{|c|}{ Grupo T } & \multicolumn{2}{|c|}{ Grupo SS } & \multicolumn{2}{|c|}{ Grupo TS } \\
\hline & $M$ & DP & $M$ & DP & $M$ & DP & $M$ & DP \\
\hline \multirow[t]{2}{*}{ Glicose } & 81,37 & 8,95 & 85,50 & 7,42 & 100,22 & $5,91^{*}$ & 108,25 & $6,18^{*+}$ \\
\hline & \multicolumn{2}{|c|}{$(n=8)$} & \multicolumn{2}{|c|}{$(n=8)$} & \multicolumn{2}{|c|}{$(n=9)$} & \multicolumn{2}{|c|}{$(n=9)$} \\
\hline \multirow[t]{2}{*}{ Colesterol total } & 29,28 & 2,13 & 28,37 & 3,24 & 34,57 & $3,73^{*}$ & 35,67 & $2,58^{*+}$ \\
\hline & \multicolumn{2}{|c|}{$(n=8)$} & \multicolumn{2}{|c|}{$(n=8)$} & \multicolumn{2}{|c|}{$(n=9)$} & \multicolumn{2}{|c|}{$(n=9)$} \\
\hline \multirow[t]{2}{*}{ HDL-C } & 14,42 & 1,39 & 15,71 & 1,49 & 18,00 & $1,69^{*}$ & 19,87 & $2,74^{*+}$ \\
\hline & \multicolumn{2}{|c|}{$(n=8)$} & \multicolumn{2}{|c|}{$(n=8)$} & \multicolumn{2}{|c|}{$(n=9)$} & \multicolumn{2}{|c|}{$(n=9)$} \\
\hline \multirow[t]{2}{*}{ Triacilgliceral } & 115,17 & 30,98 & 63,83 & $10,17^{*}$ & 81,42 & $13,16^{*}$ & 71,28 & $14,16^{*}$ \\
\hline & \multicolumn{2}{|c|}{$(n=8)$} & \multicolumn{2}{|c|}{$(n=8)$} & \multicolumn{2}{|c|}{$(n=9)$} & \multicolumn{2}{|c|}{$(n=9)$} \\
\hline \multirow[t]{2}{*}{ Glicogênio muscular } & 105,03 & 8,71 & 132,33 & 17,90 & 351,40 & $86,81^{*}$ & 272,63 & $47,01^{*+}$ \\
\hline & \multicolumn{2}{|c|}{$(n=5)$} & \multicolumn{2}{|c|}{$(n=5)$} & \multicolumn{2}{|c|}{$(n=6)$} & \multicolumn{2}{|c|}{$(n=9)$} \\
\hline \multirow[t]{2}{*}{ Glicogênio hepático } & 151,45 & 49,36 & 50,86 & $19,91^{*}$ & 128,57 & $46,91^{*}$ & 279,21 & $57,19^{*+}$ \\
\hline & \multicolumn{2}{|c|}{$(n=5)$} & \multicolumn{2}{|c|}{$(n=6)$} & \multicolumn{2}{|c|}{$(n=6)$} & \multicolumn{2}{|c|}{$(n=7)$} \\
\hline
\end{tabular}

Nota: Os valores estão expressos em média (M) e desvio-padrão (DP). Diferentes subscritos: *versus S; ${ }^{+}$versus T, para p<0,05. S: sedentário não suplementado; T: treinado não suplementado; SS: sedentário suplementado; TS: treinado suplementado; HDL-colesterol: lipoproteína de alta densidade; mg: miligramas; dL: decilitro; mmol: milimol; g: grama. 
500 A.E. AQUINO JUNIOR et al.

sidade e melhora o perfil lipídico, em ratos ${ }^{13,24}$. Neste sentido, comparando o grupo treinado com o grupo treinado suplementado (T versus TS), verificou-se neste estudo, massa corporal reduzida dos animais quando o exercício foi associado à suplementação alimentar, após 8 semanas (Figura 1), sem alteração no consumo alimentar (Figura 2) e na eficiência alimentar (Figura 3). Por outro lado, o exercício sem suplementação não foi capaz de promover mudança significante na massa corporal dos animais, quando comparado com os animais sedentários (S versus T) (Figura 1). Estes resultados sugerem que o CLA atua de forma efetiva no balanço energético, uma vez que também foi observada diminuição no peso relativo do tecido adiposo marrom, o qual é responsável pela termogênese, em todos os animais suplementados sedentários e treinados (Tabela 1).

Por outro lado, apesar de os animais do grupo treinado suplementado terem apresentado menor massa corporal, os tecidos adiposos visceral e epididimal apresentaram maior peso relativo em relação aos do grupo treinado - T versus TS (Tabela 1). Também houve aumento nas concentrações séricas de colesterol total e HDL-colesterol, resultados estes atribuídos apenas à suplementação com CLA, uma vez que o exercício per se, neste estudo, não promoveu mudança nestas variáveis - $\mathrm{S}$ versus $\mathrm{T}$ (Tabela 2). No entanto, a diminuição da concentração de triacilglicerol observada neste estudo mostrou ter relação tanto com exercício como com a suplementação com CLA (S versus T e S versus SS). Já quando o exercício foi associado à suplementação, a concentração de triacilglicerol não apresentou diferença significante em relação ao grupo treinado e sedentário suplementado (T versus TS e SS versus TS), sugerindo que a associação destes tratamentos não potencializa o efeito observado individualmente, como mostra a Tabela 2. Diferentemente destes resultados, estudo utilizando coelhos suplementados com uma mistura de isômeros de CLA apresentou aumento significativo na concentração sérica de colesterol total e diminuição do HDL-colesterol, mostrando que os mecanismos de ação do CLA ainda são inconclusivos ${ }^{25}$.
Observou-se aumento na glicemia de jejum (Tabela 2), tanto dos animais sedentários suplementados como dos treinados suplementados ( $T$ versus TS, S versus TS), podendo este efeito ser conseqüência da suplementação com este ácido graxo. O ácido linoléico conjugado, de acordo com algumas evidências, altera o metabolismo hepático causando efeitos adversos na homeostase glicêmica em camundongos ${ }^{25}$. Os resultados do atual estudo corroboram essas evidências.

Alguns estudos apontam que exercícios de intensidade baixa e moderada associados à suplementação alimentar com CLA, promovem aumento da glicemia ${ }^{16,26}$ e redução da insulinemia ${ }^{2,26}$, bem como aumento no consumo energético de ácidos graxos, o que, provavelmente, eleva os níveis de glicogênio hepático e muscular ${ }^{16,27}$, devido à maior disponibilidade de lipídios como substrato energético, poupando o glicogênio. Tais resultados podem ser confirmados pelo estudo atual, uma vez que o valor glicêmico do grupo treinado suplementado encontra-se mais alto do que o do grupo sedentário sem suplementação (S versus TS), bem como os teores de glicogênio hepático e muscular (Tabela 2). No entanto, esta adaptação nos teores de glicogênio muscular e hepático não foi observada no grupo treinado, uma vez que não houve diferença significante nos estoques de glicogênio muscular em relação ao sedentário (S versus T). Por outro lado, o glicogênio hepático apresentou-se diminuído, provavelmente devido à sua utilização como substrato energético durante o jejum, mantendo a glicemia em valores controle (Tabela 2). Confirmando os achados da literatura, observa-se, neste estudo, que o exercício moderado de natação, quando associado à suplementação com ácido linoléico conjugado, promove adaptações metabólicas tanto musculares quanto hepáticas, aumentando os estoques de glicogênio nestes tecidos (T versus TS). O CLA aumenta o teor lipídico da dieta, por ser um tipo de ácido graxo. Desse modo, os resultados deste estudo podem indicar, com relação aos estoques de glicogênio, que, quando o treinamento moderado é associado à suplementação, ocorre um meca- 
nismo de adaptação poupador de glicogênio, o qual tenta estocar primeiramente energia na forma de substrato lipídico, para ser utilizado como fonte energética em futuras sessões de exercício.

\section{O N C L U S Ã O}

De acordo com os resultados obtidos neste estudo, a suplementação com ácido linoléico conjugado, quando associada à prática de exercício físico, parece ter influência no balanço energético, uma vez que reduziu a massa corporal dos animais sem alterar a ingestão alimentar, após 8 semanas de tratamento. Houve também contribuição para melhora nas variáveis do perfil lipídico. Por outro lado, esses animais apresentaram maior adiposidade intra-abdominal e aumento na glicemia de jejum. Considerando o fígado o maior órgão responsável pela homeostase glicêmica, o aumento no peso relativo deste órgão, observado neste estudo com o uso do CLA como suplemento alimentar, indica que a ingestão deste ácido graxo pode ter efeitos indesejáveis, como o aumento nas chances de desenvolvimento do fígado gorduroso. Estes achados apontam perspectivas para novos estudos do efeito do ácido linoléico conjugado, envolvendo análises histológicas do fígado, expressão gênica de enzimas chaves do metabolismo lipídico e de carboidratos associados ou não a diferentes protocolos de treinamento físico.

\section{COLABORADORES}

A.E. AQUINO JUNIOR foi responsável pela pesquisa, pelo experimento, pela análise estatística e pela redação do manuscrito. G.K.Z.S. DOURADO contribuiu com a pesquisa e a realização do estudo experimental. F.O. DUARTE contribuiu com o embasamento teórico, a redação do manuscrito e as técnicas laboratoriais utilizadas no estudo. A.C.G.O. DUARTE co-orientadora do estudo - contribuiu disponibilizando os equipamentos e as dependências do Laboratório de Nutrição e Metabolismo e co-orientando o estudo. M. SENE-FIORESE orientadora do estudo, contribuiu com a apresentação dos métodos e das técnicas utilizadas na pesquisa e com o delineamento experimental e estatístico.

\section{REFERÊ NCIAS}

1. Mourão DM, Monteiro JBR, Costa NMB, Stringheta PC, Minim VPR, Dias CMGC. Ácido linoléico conjugado e perda de peso. Rev Nutr. 2005; 18(3): 391-9.

2. Faulconnier $Y$, Arnal M-A, Mirand PP, Chardigny JM, Chilliard Y. Isomers of conjugated linoleic acid decrease plasma lipids and stimulate adipose tissue lipogenesis without changing adipose weight in post-prandial adult sedentary or trained Wistar rat. J Nutr Biochem. 2004; 15(9):741-8.

3. Pariza MW, Park Y, Cook ME. The biologically active isomers of conjugated linoleic acid. Prog Lipid Res. 2001; 40(4):283-98.

4. Wang YW, Jones PJH. Conjugated linoleic acid and obesity control: efficacy and mechanisms. Int J Obes (London). 2004; 28(8):941-55.

5. Sisk MB, Hausman DB, Martin RJ, Azain MJ. Dietary conjugated linoleic acid reduces adiposity in lean but not obese zucker rats. J Nutr. 2001; 131(6): 1668-74.

6. Deckere EAM, van Amelsvoort JMM, McNeill GP, et al. Effects of conjugated linoleic acid (cla) isomers on lipid levels and peroxisome proliferation in the hamster. Br J Nutr. 1999; 82(4):309-17.

7. Park Y, Albright KJ, Liu W, Storkson JM, Cook ME, Pariza MW. Effect of conjugated linoleic acid on body composition in mice. J Lipids. 1997; 32(8): 853-8.

8. Taylor CG, Zahradka P. Dietary conjugated linoleic acid and insulin sensitivy and resistance in rodent models. Am J Clin Nutr. 2004; 79 (6):1164S-8S.

9. Hargrave KM, Azain MJ, kachman SD, Miner JL. Conjugated linoleic acid does not improve insulin tolerance in mice. Obes Res. 2003; 11(9):1104-15.

10. Smedman A, Vessby B. Conjugated linoleic acid supplementation in humans. Metabolic Effects. 2001; 36(8)773-81.

11. Thibault L, Woods SC, Westerterp-Plantenga MS. The utility of animal models of human energy homeostasis. Br J Nutr. 2004; 92(13 Suppl 1): S41-5.

12. Manzoni MSJ, Rossi EA, Carlos IZ, Vendramini RC, Duarte AC, Dâmaso AR. Fermented soy products supplemented with isoflavonas affected fat depots in juvenile rats. Nutrition. 2005; 21(10):1018-24.

13. Duarte FO, Sene MO, Oishi JC. O exercício de final de semana contribui para o controle das dislipidemias em ratos adultos machos alimentados com dieta rica em gorduras. Rev Bras Fisioter. 2003; 7(3):229-35. 
502 A.E. AQUINO JUNIOR et al.

14. Botelho AP, Santos-Zago LF, Reis SMPM, Oliveira AC. A suplementação com ácido linoléico conjugado reduziu a gordura corporal em ratos Wistar. Rev Nutr. 2005; 18(4):561-5.

15. Duarte ACGO, Fonseca DF, Manzoni MSJ, Soave $C F$, Sene-Fiorese M, Dâmaso AR, et al. Dieta hiperlipídica e capacidade secretória de insulina em ratos. Rev Nutr. 2006; 19(3):341-8.

16. Mizunoya W, Haramizu S, Shibakusa T, Okabe $Y$, Fushiki T. Dietary conjugated linoleic acid increases endurance capacity and fat oxidation in mice during exercise. Lipids. 2005; 40(3):265-71.

17. Miner JL, Cederberg CA, Nielsen MK, Chen X, Baile CA. Conjugated linoleic acid (CLA), body fat, and apoptosis. Obes Res. 2001; 9(2):129-34.

18. Azain MJ, Hausman DB, Sisk MB, Flatt WP, Jewell DE. Dietary conjugated linoleic acid reduces rat adipose tissue cell size rather than cell number. J Nutr. 2000; 130(6):1548-54.

19. Takahashi Y, Kushiro M, Shinohara K, IT. Dietary conjugated linoleic reduces body fat mass and affects gene expression of proteins regulating energy metabolism in mice. Comp Biochem Physiol Biochem Mol Biol. 2002; 133(3):395-404.

20. Westerterp KR. Diet induced thermogenesis. Nutr Metab (London).2004; 1(1):1-5.

21. Belury MA. Dietary conjugated linoleic acid in health: physiological effects and mechanisms of action. Ann Rev Nutr. 2002; 22(4):505-31.

22. Ohnuki K, Haramizu S, Ishihara K, Fushiki T. Increased energy metabolism and suppressed body fat accumulation in mice by a low concentration of conjugated linoleic acid. Biosci Biotechnol Biochem. 2001; 65(10):2200-4.

23. Saris WHM, Blair SN, van Baak MA, Eaton SB, Davies PSW, Di Pietro L, et al. How much physical activity is enough to prevent unhealthy weight gain? Outcome of the IASO 1st Stock Conference and consensus statement. Obes Rev. 2003; 4(2): 101-14.

24. Burneiko RCM, Diniz YS, Galhardi CM, Rodrigues $H G$, Ebaid LA, Padovani CR, et al. Interaction of hypercaloric diet and physical exercise on lipid profile, oxidative stress and antioxidant defenses. Food Chem Toxicol. 2006; 44(7):1167-72.

25. Larsen TM, Toubro S, Astrup A. Efficacy and safety and dietary supplements containing CLA for the treatment of obesity: evidence from animal and human studies. J Lipid Res. 2003; 44(12): 2234-41.

26. Bhattacharya A, Rahman $M$, Sun D, Lawrence $R$, Mejia W, McCarter R, et al. The combination of dietary conjugated linoleic acid and treadmill exercise lowers gain in body fat mass and enhances lean body mass in high fat-fed male balb/c mice1. J Nutr. 2005; 47(8):1124-30.

27. Bernardes D, Manzoni MSJ, Souza CP, Tenório N, Dâmaso AR. Revista Brasileira de Educação Física e Esportes: efeitos da dieta hiperlipídica e do treinamento de natação sobre o metabolismo de recuperação ao exercício em ratos. Exercício. 2004; 18(2):191-200.

Recebido em: 28/9/2007

Versão final reapresentada em: 25/11/2008 Aprovado em: 30/3/2009 